\title{
Lo personal es político: vida íntima y estructuras sociopolíticas en la narrativa española reciente
}

\section{The Personal is Political: Private Life and Socio-Political Structures in Recent Spanish Prose Fiction}

Mélanie Valle Detry [vcmelanie@gmail.com]

\section{RESUMEN}

En consonancia con las reivindicaciones feministas de las primeras décadas del siglo XXI, algunas escritoras han puesto de relieve la desatención o incluso el expolio del cuerpo femenino junto con una pobreza económica feminizada en la sociedad contemporánea. En narraciones de corte autobiográfico, Jana Leo, Marta Sanz, Gabriela Wiener y Silvia Nanclares demuestran que el eslogan feminista de los años setenta "Lo personal es político" aún es de actualidad y que lo íntimo no se puede desvincular de estructuras sociopolíticas.

\section{Palabras Clave}

Feminismo; autobiografía; cuerpo; economía; Jana Leo; Marta Sanz; Gabriela Wiener; Silvia Nanclares

\begin{abstract}
In agreement with the feminist vindications of the beginning of the 21st century, some female authors have highlighted the inattention or even the pillaging of the female body as well as women's economical poverty in contemporary society. In their autobiographical stories, Jana Leo, Marta Sanz, Gabriela Wiener and Silvia Nanclares demonstrate that the feminist slogan of the seventies "The personal is political" is still an ongoing fight and that intimacy cannot be separated from sociopolitical structures.
\end{abstract}

\section{KEYWORDS}

Feminism; Autobiography; Body; Economy; Jana Leo; Marta Sanz; Gabriela Wiener; Silvia Nanclares

RECIBIDO 2021-06-30; ACEPTADO 2021-08-05 
En las dos primeras décadas del siglo XXI, el movimiento feminista ha ganado resonancia tanto en España como en gran parte del mundo con, por ejemplo, marchas multitudinarias en contra de la violencia de género o para exigir el derecho al aborto, movimientos de apoyo a las víctimas de violación en redes sociales o huelgas para denunciar las desigualdades de género en el ámbito laboral o doméstico. Estas batallas han sido largas y duras y queda mucho camino por recorrer, pero también se deben reconocer las victorias conseguidas gracias a la presión social feminista como la reciente legalización del aborto en Argentina. Además de librarse en la calle, la lucha por la igualdad se ha plasmado en el ámbito cultural. Así, en el campo literario español, algunas escritoras han cuestionado la realidad social dominante a través de relatos íntimos de carácter autobiográfico.

Son ejemplos de ello Violación Nueva York (2017) de Jana Leo; Clavícula (2017) de Marta Sanz; Nueve lunas (2009) de Gabriela Wiener'; y Quién quiere ser madre (2017) de Silvia Nanclares. En estas obras, las autoras narran una vivencia personal mostrando su interrelación con las estructuras socioeconómicas actuales y denuncian la poca, mala o nula atención a las mujeres en el ámbito público. El vaivén constante de lo personal a lo político difumina las fronteras que se suelen establecer entre estos dos ámbitos y vincula las reivindicaciones de las autoras con el lema feminista de los años setenta "Lo personal es político" adaptándolo a las circunstancias actuales y discrepando, a veces, con algunos de los fundamentos de antaño.

Para analizar la interrelación entre lo personal y lo político, adoptaré un enfoque heredero del feminismo materialista prestando atención a aspectos económicos y al cuerpo como lugares de dominación del patriarcado y, al mismo tiempo, como vías para la insubordinación feminista. Con tal objetivo, me basaré en la teoría desarrollada por Silvia Federici en Calibán y la bruja. Mujeres, cuerpos y acumulación originaria (2010). En la introducción, la crítica italo-estadounidense sitúa su obra en un triple "marco conceptual": "el feminista, el marxista y el foucaultiano" (Federici 2010: 22) con los que dialoga para mostrar sus aportes y deficiencias. De este modo, vincula los orígenes del capitalismo con la caza de brujas y la desposesión violenta de las mujeres de sus derechos productivos -relegando su rol a la esfera doméstica- y reproductivos -al perder el control sobre su propio cuerpo-:

En la sociedad capitalista, el cuerpo es para las mujeres lo que la fábrica es para los trabajadores asalariados varones: el principal terreno de su explotación y resistencia [...]. En este sentido, es bien merecida la importancia que ha adquirido el cuerpo, en todos sus aspectos -maternidad, parto, sexualidad-, tanto dentro de la teoría feminista como en la historia de las mujeres. Calibán y la bruja corrobora también el saber feminista que se niega a identificar el cuerpo con la esfera de lo privado y, en esta línea, habla de una "política del cuerpo". (Federici 2010: 29-30)

Las cuatro narraciones elegidas abordan "todos los aspectos" del cuerpo con el objetivo de darles visibilidad, problematizar representaciones comunes y también con metas catárticas.

Aunque sean culturalmente privilegiadas, Leo, Sanz, Wiener y Nanclares comparten un modo de vida precario, por el trabajo que realizan, la ausencia del mismo o por ser inmigrantes. Esta "feminización de la pobreza" es, en palabras de Federici, "el primer efecto del desarrollo del ca-

1 Gabriela Wiener es peruana. Aun así la incluyo en este análisis por escribir desde España y por el interés de su propuesta narrativa. Por otra parte, quiero señalar aquí que en febrero de 2021 salió una nueva edición "revisada y ampliada" de Nueve lunas que no he podido consultar para este artículo. 
pitalismo sobre las vidas de las mujeres" (Federici 2010: 32), un efecto que se ha acentuado de nuevo con la globalización y las sucesivas crisis económicas. De hecho, las cuatro narraciones se deben relacionar con la crisis financiera que se inició en 2008 y cuyos efectos (desahucios, cierre de periódicos, pérdida de puestos y derechos laborales, etc.) condicionan la vida de las cuatro escritoras.

Las condiciones económicas están en el meollo de la narración de $\mathrm{Leo}^{2}$. Cuando Leo y su novio se mudan a Nueva York para trabajar en la universidad, tienen que buscar un piso en un barrio periférico o pobre porque sus sueldos no les permiten otra cosa. Acaban viviendo en Harlem, un barrio pobre, con mucha delincuencia y donde viven mayoritariamente afroamericanos e inmigrantes. Poco después de la mudanza, en enero de 2001, Leo es violada en su propio piso por un hombre armado. A raíz de esto, Leo empieza a investigar sobre violaciones en relación con los espacios físicos (ciudades, barrios, cárceles, casas particulares) y con el nivel socioeconómico de agresores y víctimas. Sus conclusiones son aterradoras: una de cada diez mujeres es violada (Leo 2017: 88), las mujeres pobres tienen una probabilidad mucho más alta de ser violadas (Leo 2017: 89) y las violaciones tienen lugar mayoritariamente en el ámbito doméstico. Leo insiste reiteradamente en este punto: en contra de todos los clichés y recomendaciones comunes, la casa, el hogar familiar, no es un lugar seguro (Leo 2017: 51-53, 80-89, 143-152, 158).

El ámbito doméstico también es la casa de familiares, la escalera común del edificio, el portal, los pocos metros hasta los contenedores de la basura, o sea, lugares en los que las mujeres se sienten a salvo y donde la gran mayoría de las agresiones ocurren. A Leo la sorprendió su agresor en el rellano de la escalera y, por poner otro ejemplo entre muchos, la víctima del mediático "caso de la manada"3 fue violada en un portal. A pesar de esta recurrencia, pese al alto número de casos, ninguna autoridad se muestra interesada ni dispuesta a proteger a las mujeres. Como constata Leo, "ni en España ni en Estados Unidos hay una legislación que regule que la arquitectura sea segura contra agresiones y violación" (Leo 2017: 145). La autora incluso redacta un informe "El portal, la complicidad de la arquitectura en la violencia de género, los puntos ciegos", cuyas conclusiones -la necesidad de impedir la invisibilidad de las agresiones a mujeres- fueron mandadas a "Gerencia de Urbanismo del Ayuntamiento de Madrid, así como al Defensor del Pueblo, sin que hubiera reacción alguna por cualquier lado" (Leo 2017: 147).

Este ninguneo se acrecienta cuando las víctimas son pobres -y, más aún, si el violador es blanco y rico, como ilustra el caso de Brock Turner (Leo 2017: 153)-. Leo tiene que esperar seis años para que el violador, por un lado, y el propietario del edificio, por otro, sean juzgados y finalmente condenados. Está, por consiguiente, inmersa en la violación durante todos estos años. Además, tras la violación, cada vez que llama para conocer el estado del caso, recibe respuestas desganadas, lo que acaba por interpretar como prueba de que "solo era otra mujer violada en un barrio pobre" (Leo 2017: 56). Por su parte, el agente del casero se niega a arreglar la cerradura rota de la puerta principal y, ante la insistencia de Leo que le recuerda que la han violado, le contesta: "Como si te matan"

2 Los eventos narrados en Violación Nueva York son anteriores a la crisis financiera de 2008 mencionada antes. Dicho esto, su redacción es posterior y los entramados entre violencia sistémica y el ámbito inmobiliario y financiero que Leo destapa se relacionan estrechamente con ésta.

3 El 7 de julio de 2016, una joven madrileña fue violada por un grupo de cinco hombres que, en su grupo de Whatsapp, se llamaban "La manada". Durante el juicio del caso, se produjeron protestas sociales masivas y en varias ocasiones, para apoyar a la víctima o rechazar la sentencia emitida. 
(Leo 2017: 57). Así llega la escritora a la conclusión de que "ser pobre no solo es una condición, sino un calificativo. Pobre define a la persona como alguien que carece de valor" (Leo 2017: 59).

La relación entre pobreza, violación y racismo que Leo pone de relieve se puede relacionar con el sistema capitalista:

[E]l capitalismo, en tanto sistema económico-social, está necesariamente vinculado con el racismo y el sexismo. El capitalismo debe justificar y mistificar las contradicciones incrustadas en sus relaciones sociales [...] denigrando la "naturaleza" de aquellos a quienes explota: mujeres, súbditos coloniales, descendientes de esclavos africanos, inmigrantes desplazados por la globalización. (Federici 2010: 32)

Si hoy se habla de violaciones y violencia machista (en la prensa como la española, en el día a día), en 2001, cuando Leo es violada, el carácter sistémico de la violencia machista era menos aparente. Leo es, de alguna forma, una pionera en el esfuerzo de visibilización y denuncia de un acto de agresión sistémico. Sin embargo, su relato, y en particular la versión española publicada en $2017^{4}$, se inserta en un movimiento colectivo de concienciación y denuncia que incluye, por ejemplo, el movimiento \#Metoo (iniciado también en 2017) o la aparición de términos como "femicidio" en los medios de comunicación.

Leo muestra, finalmente, cómo la delincuencia en Harlem fue en realidad propiciada por grandes propietarios inmobiliarios que, tras devaluar bloques de edificios y ahuyentar a sus inquilinos por el nivel de inseguridad y violencia cotidiana, han podido reconstruir manzanas enteras con pisos de lujo (Leo 2017: 43 y sigs.). Leo relaciona así su violación con la burbuja inmobiliaria neoyorquina:

Violación Nueva York, haciendo zoom, parte desde lo abstracto de un sistema para llevar el foco hacia un caso concreto, y cuenta cómo Nueva York «viola», y qué es violar y ser violado. [...] Quise escribir de una forma personal, aunque sin perder de vista lo que cada cosa significa a gran escala, haciendo un análisis de la situación, pero volviendo a lo más íntimo, puesto que estoy hablando de mi propia violación. (Leo 2017: 133)

La narración de Leo efectúa un movimiento continuo de ampliación de lo "micro", íntimo y personal, a lo "macro", público y político; yendo de su experiencia particular al contexto socioeconómico global y volviendo a lo íntimo. Narrando el calvario que sufrió, Leo busca superar el trauma y, al mismo tiempo, muestra los intersticios en los que se desdibujan las fronteras entre lo personal y lo político: su violación no es un caso aislado sino el resultado de un sistema económico que fomenta la violencia contra los colectivos más débiles, entre ellos, las mujeres, las personas pobres y las personas racializadas.

4 "Leo publica su narración en inglés en 2009. La traducción española es posterior y cuenta con un epílogo donde la autora se centra en la situación inmobiliaria y los casos de violación en España".

5 Según las palabras empleadas por una amiga y lectora de Leo citadas en Violación Nueva York: "Es muy inquietante y perturbador, la forma en que lo micro -la violencia contra ti, tu cuerpo, tu hogar- es una expresión de lo macro, las reglas despiadadas del poder de las promotoras inmobiliarias en la ciudad de Nueva York" (Leo 2017: 168). 
El relato de Marta Sanz en Clavícula sigue el mismo ir y venir de lo micro a lo macro, desmarcando las fronteras entre uno y otro. Clavícula se construye alrededor de un dolor físico que la autora y narradora intenta nombrar, explicar, controlar, ya que está afectando su vida diaria. Sanz inscribe su dolor, su relato autobiográfico, en una reflexión sobre realidad y ficción y la posibilidad de contar el dolor en relación con sus condiciones materiales. Al contrario de la narración de Leo, bien hilada y escrita con un estilo casi ensayístico, el relato de Sanz se compone de fragmentos heterogéneos, con una extensión desde unas líneas hasta doce páginas ${ }^{6}$ de largo. Se forma así un texto "descompuesto", como el cuerpo de la propia escritora, un texto que no avanza en línea recta sino que parece seguir la forma ondulada del hueso que da título a la novela.

¿Cómo contar el dolor? ¿Cómo nombrarlo, explicarlo, apaciguarlo? ¿Será el dolor verdadero si no consigue identificarlo ni tratarlo nadie? Imaginar que el dolor que la afecta es ficticio, un producto de su imaginación, es una preocupación esencial para Sanz, algo que motiva y justifica la narración: "Voy a contar lo que me ha pasado y lo que no me ha pasado. La posibilidad de que no me haya pasado nada es la que más me estremece." (Sanz 2017: 11). Desde el primer momento, la autora subraya que ella es "una bestia extremadamente racional" (Sanz 2017: 13) y el miedo a no padecer de un dolor verdadero, a que la angustia, el estrés, un pánico irracional se adueñen de su mente y de su vida preocupa a la novelista. A lo largo de las páginas y para su gran asombro, se muestra alternativamente fuerte (capaz de contar un viaje de trabajo con alegría a su marido, aceptando trabajos, etc.) y vulnerable ante marido, amigos y médicos. La narración oscila, de esta forma, entre lo racional y la locura, lo individual y lo colectivo, la realidad y la ficción sin que las lectoras ni la narradora puedan dibujar límites claros entre unos y otros.

El miedo a padecer de una enfermedad grave, mortal, se junta con el miedo a "no poder trabajar” (Sanz 2017: 54). Desde los primeros fragmentos, Sanz pone de relieve su condición económica: su marido no trabaja y ella asume la subsistencia económica a base de conferencias, promoción de libros, derechos de autor, artículos, etc. Hace cuentas y revela los importes de sus ingresos y gastos mensuales mostrando una preocupación económica de clase:

Los hijos de los camareros, de los mecánicos, de los campesinos, incluso los hijos de los profesionales liberales de primera generación, somos el proletariado de la letra. Lejos quedaron los tiempos en que la cultura era un elemento de desclasamiento positivo. [...] Hay una desproporción enorme, un inmenso desajuste entre esfuerzo y remuneración que me obliga a multiplicar el número de mis trabajos para poder mantener mi nivelito de vida. [...]

Mi dolor es una letra que se escribe cuando tengo miedo de no poder pagar las facturas o subvencionar una vejez sin olor a vieja. Creo que esta confesión es absolutamente impúdica pero fundamental. (Sanz 2017: 69)

Sanz relaciona su relato autobiográfico con un relato plural, el del "proletariado de la letra", a veces del proletariado a secas, y en algunas partes con el de "mujeres [...] españolas y blancas, posiblemente feministas, posiblemente de izquierdas" (Sanz 2017: 35). De esta manera, el relato cobra sentido por la relación que establece su autora entre su dolor particular y un dolor más amplio, de carácter socioeconómico.

6 Solo hay un fragmento de doce páginas. En este, Sanz incluye el cuento "Buscamos una amapola que no se marchite" publicado en el libro colectivo Drogadictos (2017). 
La precariedad por sí sola no explica, sin embargo, el malestar físico de Sanz. La autora cuenta su epopeya por la sanidad pública española en pos de explicaciones y remedios. Tiene citas con médicos de cabecera siempre distintos a quienes tiene que contar desde cero lo que la trae a la consulta, le realizan varias pruebas (a veces, tras mucho rogar) y todas salen negativas. Todo parece apuntar a un problema psicosomático pero entonces Sanz pone de realce las deficiencias de la medicina convencional respecto a la salud de las mujeres. Enumera enfermedades como la fibromialgia, la endometriosis o la costocondritis que suelen padecer las mujeres y que son mal diagnosticadas o poco conocidas por la comunidad médica: "enfermedades misteriosas, enfermedades que se colocan en el límite de lo psiquiátrico y lo muscular, a través de lo neurológico” (Sanz 2017: 134). La sintomatología de enfermedades conocidas puede ser, además, distinta para mujeres y hombres. Ahora bien, como "los libros están escritos según un patrón masculino" (Sanz 2017: 162), no siempre se toman en cuenta estas diferencias y se pasan por alto enfermedades graves. Corrobora este menosprecio por la salud de las mujeres y el cuerpo femenino la médica Carme Valls en una entrevista acerca de su libro Mujeres invisibles para la medicina (Capitán Swing, 2020):

[e]n la atención a las mujeres se mezclan los estereotipos con la falta de ciencia. La ciencia médica es androcéntrica, ha estudiado fundamentalmente lo que les pasa a los hombres [cisgénero]. Lo que pasa a las mujeres parece que es menos importante y si se sale mucho de la norma masculina es, directamente, ignorado. Me refiero por ejemplo a todo lo que tiene que ver con la menstruación, el parto, el postparto y la menopausia. [...] Cuando una mujer está en la consulta por cosas que a los hombres no les pasan, o que no les pasan igual, hay la maldita tendencia a decir que son nervios. Y cuando la medicina dice esto, además de equivocarse muchas veces, lo que hace es medicalizarlas. (Valls citada en Rigol 2021)

Sanz toma lorazepam para vencer el insomnio, una pastilla para aplacar los nervios, por lo tanto. La autora reflexiona sobre su dependencia al fármaco en varios fragmentos y en el cuento "Buscamos una amapola que no se marchite" incluido en la narración.

Sanz no es la única que denuncia las carencias de un "sistema sanitario patriarcal" (Nanclares 2017: 196). En Quién quiere ser madre, Nanclares muestra cómo numerosas enfermedades y patologías vinculadas con el sistema reproductivo femenino están “invisibilizadas" (Nanclares 2017: 196) y se queja de la ausencia de información sobre los ciclos reproductivos durante la infancia y la adolescencia: "el por qué [de este desconocimiento] es claro: todo lo que rodea a la salud y el cuerpo de la mujer, a la cultura asociada a su género está devaluado. Pero peor que la devaluación es la negación" (Nanclares 2017: 96). La negación ocurre bajo la forma del silencio sobre la existencia de la regla en la niñez o sobre los "embarazos no llevados a término" (Nanclares 2017: 97), lo que implica además el arraigo de lugares comunes y la "inexistencia de vocabulario" (Nanclares 2017: 96) propio para referirse a todo ello. Nanclares puntualiza que, en este caso, el feminismo se ha quedado corto: "La sabiduría acerca de la anticoncepción es el valioso fruto de la lucha histórica del feminismo. Para la otra batalla, la del conocimiento del cuerpo, la de la salud reproductiva, nos hemos quedado con las fuerzas mermadas" (Nanclares 2017: 97). Este reparo se está, no obstante, enmendando poco a poco, prueba de ello son libros como el de Valls.

Preocupación económica y desconocimiento del cuerpo femenino se combinan, en el caso de Sanz, con la menopausia, otra de las grandes ignoradas de la medicina, como señala Valls en la 
entrevista citada antes. Sanz inscribe su dolor en este período vital y subraya la nula importancia que tiene en las consultas médicas y el desajuste existente entre realidad y ficción en relatos literarios, los suyos incluidos. Sanz escribe: "Nadie pronuncia la palabra menopausia. Es un tótem o un tabú" (Sanz 2017: 52) y añade en el fragmento siguiente: "Nadie pronuncia la palabra menopausia ni sabe explicar por qué justo antes de que mi cuerpo experimente su combustión minúscula [...], siento que algo va muy mal, que todo lo malo va a suceder de una manera inminente" (Sanz 2017: 53). Siguiendo a Federici, se puede sugerir que, según la lógica capitalista, una mujer que deja de ser fértil pierde una de sus funciones esenciales -la reproductiva- y no merece, por lo tanto, ningún interés.

"Escribo de lo que me duele" (Sanz 2017: 51) repite Sanz en entrevistas, y esta vez sus palabras cobran un sentido literal. La búsqueda de palabras para nombrar este dolor, la necesidad de identificar lo que le pasa y el desconcierto de la autora ante pruebas negativas no se ciñen a su vida íntima sino que se interrelacionan con un contexto socioeconómico más amplio, con ámbitos públicos como el de la salud y con la desigualdad de género que lo atraviesa todo. Sanz pide respuestas a su malestar y así pone de realce la importancia de una sanidad pública de calidad y sin sexismo, así como de condiciones de trabajo justas que garanticen su salud y vejez - nuestra salud y vejez-.

Wiener y Nanclares nos llevan a un período anterior a la menopausia: el del embarazo y la reproducción. La escritora y periodista peruana dirige su mirada crítica hacia su embarazo y el parto y la crianza por venir. Por su parte, Nanclares se sitúa en un punto intermedio, viendo cómo disminuye su fertilidad por su edad y con un fuerte deseo de ser madre. De nuevo, una experiencia personal -el embarazo, el deseo de ser madre- sirve para cuestionar estructuras sociales y culturales y dar visibilidad a experiencias comunes para muchas mujeres pero que se silencian y parecen, por lo tanto, inexistentes. Además, ambas autoras ponen de manifiesto que el feminismo es plural y que existen diferencias entre distintas olas y ramas del movimiento y pensamiento feminista.

El deseo de visibilización se hace patente con la historia misma de las dos escritoras y, además, con la de otras mujeres ${ }^{7}$. En el sexto capítulo de Nueve lunas, Wiener da voz a mujeres con experiencias de maternidad no convencionales: donación de óvulos, no-deseo de ser madre, inseminación artificial, embarazo en la cárcel, separación con la criatura, adopción. Por su parte, Nanclares empieza su relato con las historias de "los hijos de las demás", microcuentos del parto de mujeres introducidas por su nombre. Más adelante, repite la operación con las historias que hay detrás de cada embarazo: abortos espontáneos, FIV, embarazo no planeado, largas esperas, etc. Como apunta la escritora madrileña: "Estoy rodeada de historias sin nombre o de nombres sin historia final. En el limbo de la concepción y la no concepción se halla otra Historia del embarazo y la reproducción" (Nanclares 2017: 124). Los tres abortos voluntarios e ilegales que vivió Wiener y que cuenta de forma pormenorizada se deben incluir en esta Historia, ya que como señala en el segundo capítulo de su relato, "las mujeres que han abortado viven su propio dolor y luto en silencio" (Wiener 2009: 32).

Wiener descubre que está embarazada mientras se recupera de una operación. Al mismo tiempo, se le diagnostica un cáncer a su padre, se suicida una amiga y Wiener y su pareja pierden su empleo. La autora necesita un trabajo para vivir y para poder quedarse en España. La noticia

$7 \quad$ La invisibilidad es tal que, tras la publicación de Irene y el aire (2020) en la que cuenta el embarazo y parto de su hija Irene, Alberto Olmos sostiene que "al menos yo no conozco un libro así, exclusivamente sobre venir al mundo tomando un caso concreto", obviando de esta forma el relato de Wiener publicado doce años antes. 
del embarazo no llega, por cuestiones económicas y emocionales, en un momento oportuno: "Enmudecimos por unos segundos mirando el Predictor como quien mira el arma con el que va a suicidarse. Un test de embarazo es siempre una presencia intimidante, sobre todo si eres un flamante desempleado" (Wiener 2009: 13). A pesar de la situación alarmista descrita en las primeras páginas, la distancia crítica de estas líneas da tono -irónico, descarado y muchas veces gracioso- al libro entero. Wiener se aleja de los clichés sobre el embarazo típicos de los "manuales para embarazadas [...] escritos por madres completamente narcotizadas por el amor de sus hijos, sin una pizca de distancia crítica" (Wiener 2009: 15). Como apunta Gutiérrez León,

[E]l embarazo y las mujeres embarazadas parecen pertenecer al territorio de lo sagrado y como tal, no es posible hablar de ello si no es en un susurro. El embarazo y sus alrededores está resguardado bajo un manto de rosas, pero Gabriela Wiener está dispuesta a desmontar estos lugares comunes, atreviéndose a mirar, con los ojos bien abiertos y sin rendirle reverencias a este recinto sagrado. (2012: 411)

En efecto, Wiener observa los cambios que sufre su cuerpo sin romanticismo y de forma minuciosa: náuseas e hipersensibilidad que la incapacitan para pensar racionalmente junto con la desaparición del deseo sexual marcan el primer trimestre; fin de su "intensa vida social" (Wiener 2009: 85) y descubrimiento de fantasías sexuales y del porno con embarazadas en el segundo trimestre; dificultad para moverse, respirar, calambres y el "síndrome del nido" entre otros males de los últimos meses.

Los detalles que proporciona Wiener sobre su sexualidad durante el embarazo la alejan de la mujer embarazada prototípica; prototipo que se puede resumir con palabras de María Llopis: “en nuestra sociedad occidental, la maternidad se inscribe en un contexto capitalista y patriarcal en el que se desarrolla asexuada, medicalizada, biologizada y desempoderada" (Llopis 2015: contraportada). Ahora bien, en lugar de buscar un muy necesario trabajo, Wiener empieza a mirar imágenes pornográficas de mujeres embarazadas:

Pensé que sólo a mí y a otras gorditas podría darnos curiosidad otras embarazadas. Me equivocaba. Descubrí un submundo alrededor de las llamadas "panzoncitas", que se encontraba dentro del género "placeres extraños", justo al lado de zoofilia, gordas y tercera edad. Al parecer, las embarazadas éramos una especie pornográfica en sí misma, llamada "nueve lunas". (Wiener 2009: 79-80, subrayado mío)

El público lector descubre aquí que las nueve lunas que dan título a la obra no solo se refieren al tiempo de la gestación sino también a una "categoría” pornográfica en las antípodas de la imagen inmaculada del embarazo. Wiener muestra, por añadidura, cómo la pornografía clasifica a las mujeres como objetos disponibles para el disfrute (de los hombres). Los comentarios de hombres en foros citados a continuación por Wiener recuerdan las palabras de Leo cuando afirma que lo que mueve al violador "no [es] el apetito sexual [...], sino el impulso de poseer a otras mujeres" (Leo 2017: 93). Un impulso relacionado con el desarrollo de la sociedad capitalista en la que, según Federici, las mujeres se convirtieron en "un bien comunal del que cualquiera podía apropiarse y usar según su voluntad” (Federici 2011: 148). 
La excesiva medicalización del embarazo y del parto señalada por Llopis también se enfatiza en la narración de Wiener. La escritora relata las citas con la matrona, las pruebas a las que se tiene que someter por protocolo y la deshumanización de todo el proceso junto con un menosprecio y a veces maltrato flagrante. La "tercera y última cita obligada con la sanidad pública" (Wiener 2009: 124) narrada por Wiener ilustra el sentimiento de humillación de la autora al vincular la situación y sus emociones con "los años de bullying en la escuela primaria" (Wiener 2009: 125).

El parto es probablemente el momento en el que la violencia se hace más patente. Como sostiene Valls entrevistada por Meritxell Rigol, "hay violencia obstétrica. El parto es un momento en el que se ejerce mucho la relación médica de poder. Para muchas es un momento de tortura, de mucho sufrimiento" (Rigol 2021). El parto de Wiener - uno de los pocos momentos en los que abandona la ironía- ejemplifica la pérdida de libre albedrío y el sufrimiento de la parturienta reducida a un mero contenedor del que hay que extraer a una criatura. A pesar de las recomendaciones de su amiga Irene, fiel defensora del parto y de la crianza natural, la ausencia de acompañamiento emocional impide que Wiener soporte el dolor del parto. Acaba pidiendo la epidural:

Supe que había perdido la batalla, que mi parto ya no era mío. Había fracasado. [...]

Y se confirmaron todas las profecías: lo que empieza con el grito «iEpidural!» casi siempre termina con parto inducido. Pero no porque la mayoría de las mujeres embarazadas en el fondo seamos unas cobardes incapaces de llegar hasta el final solas, como sugirió esta horrible comadrona.

Es que un hospital [...] no es un lugar precisamente relajante.

Antes de llegar a esa habitación, fui devuelta una y otra vez a casa, obligada a pagar dos taxis y a soportarlos, a llamar una ambulancia, sufrí el maltrato reiterado del personal de Urgencias. (Wiener 2009: 150)

Wiener formula otra exigencia para la sanidad pública: que cuide de las mujeres embarazadas y no las deje a la suerte (del equipo de turno, del nivel de cansancio y saturación del hospital, de poder pagarse una clínica privada), que el parto no se convierta en un trauma.

La figura de la "madre biologizada" que menciona Llopis se cuestiona también en la narración de Wiener y, con más detenimiento, en Quién quiere ser madre de Nanclares. Ambas escritoras se plantean con cierto desconcierto una pregunta esencial: ¿Por qué quieren ser madres?

Wiener recorre obras mitológicas, filosóficas, literarias, cinematográficas, plásticas y performances. También recurre a la historia y a internet. De allí, recupera a figuras maternas política y culturalmente abyectas, muy alejadas de la madre dedicada a la crianza por algún supuesto deber biológico. Así, descubre a mujeres que matan a sus criaturas (Aurora Rodríguez, por ejemplo) o las comen (según visualiza en la página web Rotten.com, en relatos mitológicos o aún en cuadros de Rubens). También menciona a escritoras feministas como Casilda Rodrigáñez que abogan por una recuperación del placer y del erotismo en la maternidad o, al contrario, a las que invitaban a evitar "ser madre" y rebelarse así contra el patriarcado como Simone de Beauvoir o Adrienne Rich. Y es aquí donde se encuentra el debate central del feminismo actual en torno a la maternidad.

Mientras que las feministas de los años setenta centraron su lucha en sacar a la mujer del hogar familiar, dándole acceso al mercado laboral, a anticonceptivos y a una sexualidad placentera, en los últimos años y para disgusto de parte del feminismo, algunas mujeres han reclamado una 
vuelta al despreciado mundo de los cuidados como forma de rebelión en contra del ritmo imparable del capitalismo neoliberal. El debate está abierto y tenso. Como reconoce Esther Vivas, "el carácter biológico de la maternidad incomoda al feminismo" (Quelart 2019) y resulta difícil situarse sobre esta cuestión sin que se abran conflictos ${ }^{8}$.

Wiener refleja las posiciones enfrentadas con humor mencionando las decisiones y consejos de su amiga Irene o la "posición militante" de Aixi, ambas defensoras de la crianza natural, enfrentadas a la maternidad conductista convencional y al rechazo de los cuidados por el feminismo neoliberal. Con Aixi, escribe Wiener, "la maternidad parecía, además de un hecho natural, un hecho político" (Wiener 2009: 86) que implica una toma de posición explícita (biberón o chupete, carrito o foulard, epidural o parto sin anestesia, ...). Mientras Wiener muestra cierta atracción por una maternidad que "por primera vez en la historia [...] se percibía de una manera gozosa" (Wiener 2009: 117), reconoce que en el mercado laboral las embarazadas siguen siendo "seres antiestéticos" (Wiener 2009: 92) mostrando las tensiones e incompatibilidades entre ámbito laboral y el mundo de los cuidados, así como su propia vacilación para situarse en el debate. Así, tras sugerir que "hoy una mujer con cierto toque posfeminista tiene la opción de ser un poco de todo: [...] Una mujer liberada y la madre ideal", se pregunta Wiener: "¿Se puede con todo?" (Wiener 2009: 92).

Nanclares, por su parte, expresa explícitamente su deseo de ser madre tras la muerte de su padre y poco antes de cumplir cuarenta años. No es un deseo nuevo, pero ella, como algunas de sus amigas, lo habían postergado por razones económicas y por rechazo del "mandato de género acendrado" según el cual el destino "natural" de las mujeres es "ser madres, sin más, de serie, sin pensarlo, como lo habían sido la mayoría de nuestras progenitoras" (Nanclares 2017: 188). Sin embargo, a pesar de su bagaje feminista, de su indignación por discursos patriarcales y conservadores, Nanclares debe reconocer que la vida fértil es una realidad biológica:

Yo, que he permanecido todos estos años a salvo, del otro lado de la reja del colegio, pertrechada tras mi carpeta de estudiante, considerando que el reloj biológico era una construcción social y cultural -por no decir una patraña- me encuentro ahora obligada a pasar al otro lado de la realidad. Yo, que negué la biología como condicionante supremo, me arrodillo ahora ante sus manuales y rebusco los indicios que hagan de mi cuerpo una máquina bien engrasada. (Nanclares 2017: 74)

Llevada por una sensación de "urgencia", Nanclares consulta libros, amigas, colegas, foros y descubre -con buena dosis de humor, obsesión y distancia crítica- aplicaciones, grupos de apoyo, nutricionistas y el mundo de la reproducción asistida en la sanidad pública y clínicas privadas.

Nanclares muestra que la reproducción asistida no ha sido ni es recibida de forma unánime por los feminismos. Por un lado, las técnicas de reproducción se han visto como una nueva forma de controlar el cuerpo de las mujeres y reducirlas, en palabras de Federici, a "meros vientres" (Federici 2011:31). Por otro lado, suponen avances para, por ejemplo, madres solteras o parejas lesbianas; caso de Nieves y Mara en Quién quiere ser madre.

8 El debate entre estas dos posiciones enfrentadas dentro del feminismo se representa de forma muy caricaturesca en Feliz Final (Isaac Rosa 2018: 228-234). Fuera de la ficción, encontramos un interesante resumen de la cuestión (desde una perspectiva ecofeminista) en "La crianza con apego como desafío al capitalismo patriarcal” de Julia Cañero Ruiz (Cañero Ruiz 2018). 
En el sobresaliente capítulo “41. Hijas de la Transición”, Nanclares copia una entrada para su blog titulada "De cómo el feminismo fracasó en legitimar los cuidados y la fertilidad hizo crack" (Nanclares 2017: 190). Reflexiona allí sobre los debates entre distintas ramas del feminismo en torno a la maternidad, su postergación y la reproducción asistida. La autora sitúa el retraso de la maternidad en un momento histórico -la Transición- en el que se celebró la libertad reconquistada tras cuarenta años de dictadura. Las españolas se lanzaron entonces con entusiasmo a por títulos universitarios, empleos remunerados, viajes y experiencias sexuales no reproductivas. Ser madre joven se asociaba, según Nanclares, "al fracaso" (Nanclares 2017: 191). No obstante, la vida sin hijos no solo era fruto de una elección, sino de una inestabilidad económica y afectiva prolongada, de la ausencia de igualdad en el terreno de los cuidados y, añade Nanclares, de intereses productivos:

Perversamente, el mercado de trabajo está encantado con el retraso conquistado: más tiempo y personas productivas, menos bajas maternales y paternales, menos políticas que incentiven la conciliación [...].

Cuando los intereses productivos saludan las conquistas del feminismo, es hora de pararse a pensar que nuestra tendencia a lo mejor no es un mero cambio en costumbres reproductivas. El mercado laboral abraza la maternidad tardía con tal entusiasmo y eficacia que consigue hacernos creer que nosotras también la deseamos. (Nanclares 2017: 191-192)

La aventura de Nanclares por los mundos de la fertilidad y reproducción se presenta en las primeras páginas como un "rezo" (Nanclares 2017: 14) que recuerda al de Sanz: un intento de distanciamiento y análisis para disipar tensiones y crear un espacio para la reflexión, la esperanza y la catarsis. Su relato es el de muchas otras mujeres y sugiere que es hora de recolocar la responsabilidad de la maternidad tardía sobre los hombros del Estado 9 y del sistema económico en lugar de culpar a las madres añosas.

Para concluir, volvamos a Silvia Federici. En Calibán y la bruja, la historiadora relaciona la acumulación primitiva que permitió el asentamiento del sistema capitalista con la caza de brujas, los cercamientos y la trata de esclavos (Federici 2011: 26). Si, en la España actual, la caza de brujas parece ser un procedimiento de siglos pasados, los intentos para "disciplinar y apropiarse del cuerpo femenino" (Federici 2011: 27) siguen siendo vigentes hoy en día, de forma física con feminicidios, violaciones o violencia obstétrica; a través de la invisibilización de, por ejemplo, las pérdidas gestacionales, enfermedades femeninas y, de nuevo, la violación; y finalmente, culpando a las mujeres de forma individual y no al sistema por comportamientos irresponsables. Hay, en las cuatro narraciones, un deseo de poner el foco en estas experiencias invisibilizadas y en los vínculos que las unen con el sistema capitalista neoliberal y patriarcal; en mostrar cómo la precariedad laboral, por un lado, y, por otro, el expolio del cuerpo femenino son los sostenes de este sistema. Al incluir sus experiencias personales en un marco socioeconómico global, las autoras se empoderan y se liberan de la culpa individual y del miedo para construir una red de relatos feministas en los que oímos que definitivamente "lo personal es político". 


\section{Referencias bibliográficas}

Cañero Ruiz, J. (2018). La crianza con apego como desafío al capitalismo patriarcal. Pikara, 07.11.2018. https://www.pikaramagazine.com/2018/11/la-crianza-con-apego-como-desafio-al-capitalismo-patriarcal/

Federici, S. (2010). Calibán y la bruja. Mujeres, cuerpos y acumulación originaria. Trad. V. Hendel, \& L. S. Touza. Madrid: Traficantes de sueños.

Fernández, J. (2017). La infertilidad es una patología social a la que ha contribuido el Estado. Pikara, 29.03.2017. https://www.pikaramagazine.com/2017/03/entrevista-silvia-nanclares/

Gutiérrez León, A. (2012). Maternidad irreverente: una confesión desde el cuerpo en Nueve lunas de Gabriela Wiener. In C. Bolognese, F. Bustamante, \& M. Zabalgoitia (eds.), Éste que ves, engaño colorido... Literaturas, culturas y sujetos alternos en América Latina (pp. 409-417). Barcelona: Icaria Editorial.

Leo, J. (2017). Violación Nueva York. Barcelona: Los libros del lince.

Llopis, M. (2015). Maternidades subversivas. Tafalla: Txalaparta.

Montfort (de), J. S. (2020). Alberto Olmos: "Una de las premisas de 'Irene y el aire' era cómo no parecer el clásico pesado que cree que todo lo que le pasa lo puede contar y el lector debe leerlo". The objective, 03.11.2020. https://theobjective.com/further/alberto-olmos-premisas-de-irene-y-el-aire-no-parecer-el-clasico-pesado/

Nanclares, S. (2017). Quién quiere ser madre. Barcelona: Alfaguara.

Quelart, R. (2019). La Vanguardia, 25.05.2019. https://www.lavanguardia.com/vida/20190524/ 462419329444/esther-vivas-mama-desobediente-feminismo.html

Rigol, M. (2021). El parto es un momento en el que se ejerce mucho la relación médica de poder. Ctxt, 06.01.2021. https://ctxt.es/es/20210101/Politica/34638/Meritxell-Rigol-entrevista-Carme-Valls-mujeres-medicina-salud-parto.htm

Rosa, I. (2018). Feliz final. Barcelona: Seix Barral.

Sanz, M. (2017). Clavícula. Barcelona: Anagrama.

Wiener, G. (2009). Nueve lunas. Barcelona: Mondadori. 